\title{
Hypertension Associated with Coarction (COA) of the Aorta. Case Report from Clinical Experience in Paediatric
}

\author{
Eilaf Mohamednour, and Kirsten Wolffsohn
}

\section{ABSTRACT}

Coartion of the aorta is a birth defect, in which aorta become narrower than usual and this narrowness differ in the amount from one case to another. Occurring more frequently in boys than girls and the risk increase with family history having, bicuspid aortic valve and in Turner syndrome.

It can present with different clinical presentation depending on the severity of the narrowness; weak or no pulse in the feet and blood pressure in the arm much higher than in the legs. The aim of this case report is to emphasize special attention to coartion of aorta as cause of systemic Hypertension, delineate the difference diagnostic approach for systemic hypertension in children and adult and stress the important of doing proper clinical examination of cardiovascular examination and checking the blood pressure even in young children. Such case will help us pay attention to possibility of COA in children with hypertension.

Keywords: Coarction, HTN, Secondary HTN, Aorta.

Published Online: November 14, 2020

ISSN: $2593-8339$

DOI: 10.24018 /ejmed.2020.2.6.544

Dr Eilaf Mohamednour*

NHS Trust, UK.

(e-mail: eilaf.nour@nhs.net)

Dr Kirsten Wolffsohn

NHS Trust, UK.

*Corresponding Author

\section{CASE REPORT}

A lovely 8-year old girl with no background of medical condition. Referred by her GP due to; left ankle swelling and inability to weight bearing over it associated with blanching skin rash which later developed into petechieal and purpuric rash. Her mother observed that she had becoming more lethargic, and easy getting fatigue coupled with exercise intolerance in the last few months. In addition to experiencing central constant chest pain with no clear obvious cause which took few minutes and settled without medication. Initial differential diagnosis is HSP, then after spiking high grade fever with increased inflammatory marker sepsis was thought and started on antibiotic.

On evaluation she noted to have persistent high blood pressure with sinus tachycardia since admission. On proper physical examination: there is, active pericardium with continuous harsh systolic murmur loudest on the back over interscapular space with equal pulse in the upper limbs and absent bilateral femoral pulses. Musculoskeletal system showed; swelling and tenderness around the left leg, left foot and calf muscles with discouloration. Pale, pink mottled with decrease range of movement of left ankle.

Chest Xray and ECG were unremarkable. Chemistry, renal, liver and aldesterone level were all within normal range FBC (16000) CRP (73) coagulation is normal, fibrinogen slightly elevated; urine protein creatinine ratio is 48(high), no protein or blood in the urine. Echo showed; subclavin coartion of the aorta. Doppler u/s reveals normal flow, MRI ankle, showed infective tenosynovitis with no evidence of arthritis or osteomyelitis.

\section{CONCLUSION}

Occult aortic coartion should be suspected in hypertensive young patient. Blood measurement must be part of routine physical examination in children 3 years and older and thoroughly physical examination should be carried out for etiology of secondary hypertension. 